\title{
Chemical ageing and transformation of diffusivity in semi-solid multi-component organic aerosol particles
}

\author{
C. Pfrang ${ }^{1,2}$, M. Shiraiwa ${ }^{2}$, and U. Pöschl ${ }^{2}$ \\ ${ }^{1}$ University of Reading, Department of Chemistry, PO BOX 224, Whiteknights, Reading RG6 6AD, UK \\ ${ }^{2}$ Max Planck Institute for Chemistry, Biogeochemistry Department, PO BOX 3060, 55128 Mainz, Germany
}

Received: 24 March 2011 - Published in Atmos. Chem. Phys. Discuss.: 27 April 2011

Revised: 12 July 2011 - Accepted: 13 July 2011 - Published: 26 July 2011

\begin{abstract}
Recent experimental evidence underlines the importance of reduced diffusivity in amorphous semi-solid or glassy atmospheric aerosols. This paper investigates the impact of diffusivity on the ageing of multi-component reactive organic particles approximating atmospheric cooking aerosols. We apply and extend the recently developed KMSUB model in a study of a 12-component mixture containing oleic and palmitoleic acids. We demonstrate that changes in the diffusivity may explain the evolution of chemical loss rates in ageing semi-solid particles, and we resolve surface and bulk processes under transient reaction conditions considering diffusivities altered by oligomerisation. This new model treatment allows prediction of the ageing of mixed organic multi-component aerosols over atmospherically relevant timescales and conditions. We illustrate the impact of changing diffusivity on the chemical half-life of reactive components in semi-solid particles, and we demonstrate how solidification and crust formation at the particle surface can affect the chemical transformation of organic aerosols.
\end{abstract}

\section{Introduction}

Aerosols are highly variable components of the Earth's atmosphere that have a substantial impact on hydrological cycle, climate and public health (e.g. Seinfeld and Pankow, 2003; Pöschl, 2005; Fuzzi et al., 2006; Andreae and Rosenfeld, 2008). Gas-particle interactions can significantly change the physical and chemical properties of aerosols such as toxicity, reactivity, hygroscopicity and radiative properties (e.g. Rudich, 2003; Enami et al., 2008; Shiraiwa et al., 2011a). Thus, full understanding of the properties and transformation of aerosol particles is of key importance for at-

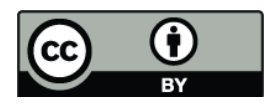

Correspondence to: C. Pfrang

(c.pfrang@reading.ac.uk) mospheric science. Aerosols may be present as solids or liquids depending on their compositions and ambient conditions (Martin, 2000; Marcolli et al., 2004; Shiraiwa et al., 2011b; Vaden et al., 2011). Until recently, secondary organic aerosol (SOA) particles formed in the atmosphere were assumed to be liquid (Hallquist et al., 2009). Virtanen et al. (2010), however, showed that biogenic SOA particles produced both in chamber experiments and during particle-formation events over boreal forests can adopt an amorphous semi-solid state, which is in line with the observed presence of oligomers with high molecular mass and low volatility in SOA (Kalberer et al., 2004). Many organic compounds, e.g. carboxylic acids, form amorphous phases upon cooling or drying of aqueous solution droplets (Murray, 2008; Zobrist et al., 2008; Mikhailov et al., 2009). These solid or semi-solid amorphous phases can be classified as glasses, rubbers, gels, or ultraviscous liquids (Mikhailov et al., 2009). The occurrence of highly viscous, glassy or gel-like substances can impact on the atmospheric fate of reactive aerosol components. The oxidation of organic substances in the atmosphere is mainly initiated by hydroxyl radicals $(\mathrm{OH})$, nitrate radicals $\left(\mathrm{NO}_{3}\right)$ and ozone $\left(\mathrm{O}_{3}\right)$ (Wayne, 2000). While atmospheric lifetimes of volatile organic compounds are largely determined by the rate coefficients of the chemical reactions with $\mathrm{OH}, \mathrm{NO}_{3}$, and $\mathrm{O}_{3}$ (e.g. King et al., 1999; Pfrang et al., 2006, 2007, 2008; McGillen et al., 2011), mass transport parameters of reactants are important additional factors for organic aerosols. Chemical reactions can occur at the surface and in the bulk of aerosol particles (e.g. Pfrang et al., 2010; Xiao and Bertram, 2011). Rates and relative proportions of surface and bulk reactions as well as the evolution of diffusivity during atmospheric ageing of multi-component aerosol particles are poorly understood.

Cooking aerosol has been recognised to contribute substantially to the urban aerosol burden. The aerosol-mass spectrometer spectra of one of its most prominent reactive components have strong similarity to oleic acid (Allan et al.,

Published by Copernicus Publications on behalf of the European Geosciences Union. 
2010). Oxidation of oleic acid and related compounds has been subject to intense experimental investigation (e.g. Ziemann, 2005; Zahardis and Petrucci, 2007; Gonzalez-Labrada et al., 2007; Lee and Chan, 2007; King et al., 2008, 2009, 2010; Vesna et al., 2009; Thompson et al., 2010; Pfrang et al., 2011) and been established as a model system for atmospheric aerosol ageing. While single-component aerosol oxidation studies provide very useful mechanistic and kinetic insight, real atmospheric aerosols consist of much more complex multi-component and multi-phase mixed particles. Recent studies of mixed particles report that the changes in viscosity and phase significantly affect atmospheric aerosol ageing (e.g. Xiao and Bertram, 2011 and references therein; Tong et al., 2011; Zobrist et al., 2011; Shiraiwa et al., 2011b). Xiao and Bertram (2011) studied a mixture of the oleic acid methyl ester, methyl oleate, in a multi-component matrix. Kinetic parameters were derived following a resistor model approach aiming to distinguish between surface and bulk reactivity. A range of laboratory studies report an impact of diffusivity changes on the ageing of aerosols containing oleic acid (e.g. Moise and Rudich, 2002; Nash et al., 2006; Zahardis et al., 2008; Last et al., 2009). Most of these studies found physical changes leading to the solidification (e.g. drying and deliquescence). A few studies reported reduced reactivity with increasing reaction time that suggests an oxidation-induced change in viscosity (e.g. Huff Hartz et al., 2007). To date, the large majority of laboratory studies provide evidence for physical - not chemical - processes altering diffusivity, but this might be due to the higher complexity of the added chemical reactions that have to be considered in studies of chemical ageing.

Moise and Rudich (2002) studied oleic acid ozonolysis in liquid and solid particles. They contrast liquid particles where sub-surface layers participate in the uptake with frozen oleic acid particles where uptake is limited exclusively to the surface. Lee and Chan (2007) studied ozonolysis of oleic acid particles in an electrodynamic balance with Raman spectroscopy. They report formation of peroxidic compounds and an increasing hygroscopicity of aged particles. They propose reaction pathways leading to formation of diperoxides and polymeric peroxides. Vesna et al. (2009) also report predominance of peroxides as secondary reaction products (Ziemann, 2005 estimated organic peroxides to contribute $68 \%$ to the total product aerosol mass) and include polymerisation channels in their reaction schemes. They found that the product distribution depends strongly on ambient relative humidity. Last et al. (2009) studied products from oleic acid ozonolysis and found that oligomer chain lengths increased with ozone exposure. Zahardis et al. (2008) studied mixed particles containing oleic acid and particulate amines. They also report stabilised Criegee intermediates and found direct evidence for the formation of a surface reaction barrier during ozonolysis of mixed oleic acid/octadecylamine particles. This reaction barrier leads to retention of oleic acid in the mixed particle even at very high ozone concentrations.
Zahardis et al. (2008) propose that this effect is caused by surface or near-surface reactions that produce high molecular weight products and that these surface active species may impede the diffusion of ozone into the particle as well as limiting the diffusion of oleic acid to the surface: this effectively shuts down oleic acid ozonolysis. Similar effects of formation of solid or highly viscous surface layers have been observed by Nash et al. (2006) for ozonised mixed oleic acidmyristic acid particles. Zahardis et al. (2008) propose that condensed phase thermochemical effects like gel or semisolid formation that may prolong oleic acid lifetimes need to be explored.

Huff Hartz et al. (2007) applied a relative rate technique to follow the kinetics of multi-component reactive organic aerosol particles. They found a retardation of the decay of oleic and palmitoleic acids and report initial and final rate coefficients differing by more than one order of magnitude. This investigation was chosen for simulation in the present modelling study, since these experimental data are very well suited for detailed analysis with our modelling tools promising new mechanistic insight by exploring diffusivity effects.

Description of the behaviour of multi-component aerosols that are realistic models for atmospheric particles remains a major challenge. In the present modelling study we applied three approaches for description of 12-component mixed organic aerosol particles: a simple model variant based on resistor model formulations (K2-SUB; Pfrang et al., 2010) is compared with a more sophisticated model (KM-SUB; Shiraiwa et al., 2010) to establish the significance of diffusion processes in semi-solid aerosol particles that cannot be resolved in resistor model formulations. In the KM-SUB modelling approach we either assume a semi-solid matrix with constant diffusivity or describe the diffusivity evolution caused by highly viscous reaction products.

\section{Methodology}

We applied two kinetic flux models to analyze the experimental results of ozone uptake by semi-solid multicomponent organic aerosol particles: the kinetic multilayer model (KM-SUB: Shiraiwa et al., 2010) and the kinetic double-layer model (K2-SUB: Pfrang et al., 2010) for aerosol surface and bulk chemistry, both of which are based on Pöschl-Rudich-Ammann framework (Pöschl et al., 2007; Ammann and Pöschl, 2007). KM-SUB explicitly treats all steps of mass transport and chemical reaction from the gasparticle interface to the particle core, resolving concentration gradients and diffusion throughout the particle bulk. Unlike traditional resistor models, KM-SUB does not require simplifying assumptions about steady-state conditions and radial mixing. Instead of explicit treatments of bulk diffusion and reaction, K2-SUB uses one layer for bulk and the diffusion and reaction in the bulk is represented by the reactodiffusive flux $\left(J_{\mathrm{b}, \mathrm{rd}, \mathrm{O}_{3}}\right)$ based on traditional resistor model 
formulations (Pöschl et al., 2007). In this approach, the nonvolatile reactant is assumed to be well mixed in the bulk of the condensed phase.

KM-SUB consists of multiple model compartments and layers: gas phase, near-surface gas phase, sorption layer, quasi-static surface layer, near-surface bulk, and a number of $n$ bulk layers. The following processes are considered in KM-SUB: gas phase diffusion and gas-surface transport (reversible adsorption) of ozone, surface and bulk reactions between ozone and each organic component, surface-bulk transport and bulk diffusion of ozone and organic multicomponents.

Surface-bulk transport and bulk diffusion of volatile and nonvolatile reactants are explicitly treated as the mass transport from one bulk layer to the next by describing the mass transport fluxes between different layers of the bulk by firstorder transport velocities, which are calculated from the bulk diffusion coefficients (Shiraiwa et al., 2010). Bulk reaction rates are calculated assuming that bulk reactions proceed with straightforward second-order rate dependences on the concentrations within each bulk layer. In the numerical simulations presented in this study, the number of model layers was set to $n=250$ for the $275 \mathrm{~nm}$-radius particle. Test calculations using a wide range of values for $n$ gave very similar results (see Fig. S5 in the Supplement).

The evolution of bulk diffusion coefficients upon products formation are implemented to KM-SUB in this study. The diffusion coefficient of ozone in the multi-component organics is evolved using the theory for diffusion in heterogeneous media, known as obstruction theory (Stroeve, 1975). Assuming the reaction products are dimmers and polymers which have much lower diffusivity compared to parent organics, the obstruction theory gives the expression for the diffusion coefficients of ozone and the organic reactant, $\mathrm{Y}$, in a medium containing a concentration fraction $f_{\mathrm{b}, n}$ of products in each layer $n$ as follows:

$$
\begin{aligned}
& D_{\mathrm{b}, \mathrm{O}_{3}, n}(t)=D_{\mathrm{b}, \mathrm{O}_{3}, 0}\left(2-2 f_{\mathrm{b}, n}\right) /\left(2+f_{\mathrm{b}, n}\right) \\
& D_{\mathrm{b}, \mathrm{Y}, n}(t)=D_{\mathrm{b}, \mathrm{Y}, 0}\left(2-2 f_{\mathrm{b}, n}\right) /\left(2+f_{\mathrm{b}, n}\right)
\end{aligned}
$$

where $D_{\mathrm{b}, \mathrm{O}_{3}, 0}$ and $D_{\mathrm{b}, \mathrm{Y}, 0}$ are the initial diffusion coefficients of ozone and $\mathrm{Y}$ in the 12-component mixture, respectively. The concentration fraction of products in the quasi-static surface layer $\left(f_{\mathrm{ss}}\right)$ is used analogously for calculation of the surface diffusion coefficients $D_{\mathrm{s}, \mathrm{O}_{3}}(t)$ and $D_{\mathrm{s}, \mathrm{Y}}(t)$. The reaction products are assumed to be (semi-)solid, so that the concentration fractions $f_{\mathrm{ss}}$ and $f_{\mathrm{b}}$ may be interpreted as degrees of solidification with a value of unity corresponding to complete conversion of reactants into (semi-)solid products. $f_{\mathrm{ss}}$ or $f_{\mathrm{b}}$ approaching unity thus leads to a shut down of transport due to massively decreasing diffusivity.

While we follow the obstruction theory approach throughout the paper, we tested the sensitivity of our modelling approach on the method used to describe the evolution of diffusivity as detailed in the Supplement material (see Fig. S4).
The alternative approach uses a linear combination expression for the time-dependent diffusion coefficients assuming a product diffusivity of $1 / 4$ of the initial value (based on a $M^{2}$ dependence for dimmer formation). There is a measurable, but not substantial difference between the two approaches. Another alternative approach, percolation theory, has been applied by Shiraiwa et al. (2011b), but constraining parameters required for application of this theory are not available for the multi-component system investigated in the present study. We thus used the obstruction theory approach which has been applied in the past (Stroeve, 1975). However, we would like to point out that representation of viscosity and diffusion in multi-component mixtures is highly uncertain: lack of miscibility may lead to phase heterogeneity and separation into domains of very different compositions and viscosities. There is no direct experimental evidence suggesting only radial heterogeneity in viscosity and discrete domains analogous to micelle formation by surfactant material in aqueous solutions may be equally as possible as formation of complete crusts.

In both models the uptake coefficients of ozone $\left(\gamma_{\mathrm{O}_{3}}\right)$ is expressed as the ratio of the net flux of $\mathrm{O}_{3}$ from the gas phase to the condensed phase to the gas kinetic flux of ozone colliding with the surface (Pöschl et al., 2007). The temporal evolution of the particle surface and bulk composition and uptake coefficient of ozone were modelled by numerically solving the differential equations for the mass balance for each model compartment with Matlab (using the ode23tb solver with 999 time steps). The initial concentrations of ozone at the surface and in the bulk were set to zero and those of the 12-mixture components are based on Huff Hartz et al. (2007). The 12 components $(9.9 \%$ unreactive alkanes, $14.9 \%$ palmitoleic acid, $13.1 \%$ oleic acid, $1 \%$ nervonic acid, $2.8 \%$ cholesterol, $2.0 \%$ decanoic acid, $17.7 \%$ palmitic acid, $22.4 \%$ stearic acid, $1.3 \%$ arachadic acid, $2.6 \%$ glutaric acid, $6.6 \%$ adipic acid, $5.8 \%$ suberic acid) have been chosen to mimic meat-cooking emission profiles in dry conditions containing the key unsaturated compounds commonly used as markers, in particular cholesterol as well as palmitoleic and oleic acids (Huff Hartz et al., 2007 and references therein). Product volatilization in the complex 12-component aerosol mixture is not considered here, mainly because of the lack of experimental data to constrain any modelling attempt. Re-condensation of components is unlikely to be of importance in the experimental conditions where gaseous components originate from the particles only. All components are assumed to be initially homogeneously mixed throughout the particle. The required kinetic parameters are listed in Table 1. The values were chosen based on previous work (Pfrang et al., 2010; Shiraiwa et al., 2011a) and to match the experimental data. Initial surface accommodation coefficient of ozone $\left(\alpha_{\mathrm{s}, 0, \mathrm{O}_{3}}=1\right)$ and desorption lifetime of ozone $\left(\tau_{\mathrm{d}, \mathrm{O}_{3}}=10^{-9} \mathrm{~s}\right)$ are based on previous studies (Shiraiwa et al., 2011a, b). Additional input parameters are: the mean thermal velocity of 
Table 1. Kinetic parameters for the interaction of ozone and multicomponent organics (compare List of symbols in Appendix A).

\begin{tabular}{ll}
\hline Parameters & Values \\
\hline$\alpha_{\mathrm{s}, 0, \mathrm{O}_{3}}$ & 1 \\
$\tau_{\mathrm{d}, \mathrm{O}_{3}}(\mathrm{~s})$ & $10^{-9}$ \\
$K_{\mathrm{sol}, \mathrm{cc}, \mathrm{O}_{3}}\left(\mathrm{~mol} \mathrm{~cm}^{-3} \mathrm{~atm}^{-1}\right)$ & $4.8 \times 10^{-4}$ \\
$D_{\mathrm{b}, \mathrm{O}_{3}, 0}\left(\mathrm{~cm}^{2} \mathrm{~s}^{-1}\right)$ & $5.5 \times 10^{-8}$ \\
$D_{\mathrm{b}, \mathrm{Y}, 0}\left(\mathrm{~cm}^{2} \mathrm{~s}^{-1}\right)$ & $3.0 \times 10^{-15}$ \\
$k_{\mathrm{SLR}, \mathrm{O}_{3}, \mathrm{ole}}\left(\mathrm{cm}^{2} \mathrm{~s}^{-1}\right)$ & $1.0 \times 10^{-10}$ \\
$k_{\mathrm{SLR}, \mathrm{O}_{3}, \mathrm{pal}}\left(\mathrm{cm}^{2} \mathrm{~s}^{-1}\right)$ & $1.6 \times 10^{-10}$ \\
$k_{\mathrm{BR}, \mathrm{O}_{3}, \mathrm{ole}}\left(\mathrm{cm}^{3} \mathrm{~s}^{-1}\right)$ & $1.0 \times 10^{-16}$ \\
$k_{\mathrm{BR}, \mathrm{O}_{3}, \mathrm{pal}}\left(\mathrm{cm}^{3} \mathrm{~s}^{-1}\right)$ & $1.6 \times 10^{-16}$ \\
\hline
\end{tabular}

$\alpha_{\mathrm{s}, 0, \mathrm{O}_{3}}:$ surface accommodation coefficient of ozone on free substrate, $\tau_{\mathrm{d}}$ : desorption lifetime of ozone, $K_{\mathrm{sol}, \mathrm{cc}, \mathrm{O}_{3}}$ : Henry's law coefficient of ozone, $D_{\mathrm{b}, \mathrm{O}_{3}, 0}$ and $D_{\mathrm{b}, \mathrm{Y}, 0}$ : bulk diffusion coefficients of ozone and organics, $k_{\mathrm{SLR}, \mathrm{O}_{3}, \text { ole }}, k_{\mathrm{SLR}, \mathrm{O}_{3}}$, pal : secondorder rate coefficients of surface reaction between ozone, and oleic acid and palmitoleic

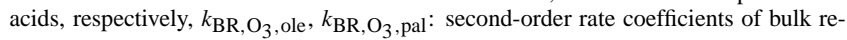
action between ozone, and oleic acid and palmitoleic acids, respectively.

ozone $\left(\omega_{\mathrm{O}_{3}}=3.6 \times 10^{4} \mathrm{~cm} \mathrm{~s}^{-1}\right)$, the Henry's law coefficient of ozone $\left(K_{\mathrm{sol}, \mathrm{cc}, \mathrm{O}_{3}}=4.8 \times 10^{-4} \mathrm{~mol} \mathrm{~cm}^{-3} \mathrm{~atm}^{-1}\right)$, and the molecular diameter of ozone and organics $\left(\delta_{\mathrm{O}_{3}}=0.4 \mathrm{~nm}\right.$, $\delta_{\mathrm{Y}}=0.8 \mathrm{~nm}$ ) (Shiraiwa et al., 2009; Pfrang et al., 2010). Second-order rate coefficients for the reaction between ozone and oleic and palmitoleic acid in the bulk $\left(k_{\mathrm{BR}}\right)$ are taken from Huff Hartz et al. (2007) and those at the surface $\left(k_{\mathrm{SLR}}\right)$ are based on Pfrang et al. (2011). The initial estimates of bulk diffusion coefficients of ozone and organics $\left(D_{\mathrm{b}, \mathrm{O}_{3}, 0}\right.$ and $\left.D_{\mathrm{b}, \mathrm{Y}, 0}\right)$ are based on Shiraiwa et al. (2011b) and they were systematically and iteratively varied using Matlab software to find the best fits. The sensitivity of each parameter on model results is discussed in the Supplement material. While experimental data are only available for the first ca. $13000 \mathrm{~s}$, the model was run for $10^{5} \mathrm{~s}$ since this is an atmospherically relevant timescale for this type of aerosol matrix.

\section{Results and discussion}

Figure 1 shows the time evolution of oleic and palmitoleic acids, the most reactive species in the 12-component mixture approximating cooking aerosols. Surface and bulk concentrations are converted into numbers of molecules to be able to show the decays in a single figure. The fitted data were obtained using variants of the detailed kinetic multilayer flux model (KM-SUB) at $130 \mathrm{ppb}\left[\mathrm{O}_{3}\right]$ with the kinetic parameters listed in Table 1 . The best fits (illustrated as solid lines) to experimental data from Huff Hartz et al. (2007)

\footnotetext{
${ }^{1}$ Only a limited timescale is accessible with standard Matlab solvers (see end of dot-dashed line in Fig. 1a) due to the steep decays. The deviation from experimental data is clearly demonstrated on the available timescale and we expect the dot-dashed line in Fig. 1a to behave like that in Fig. 1b.
}

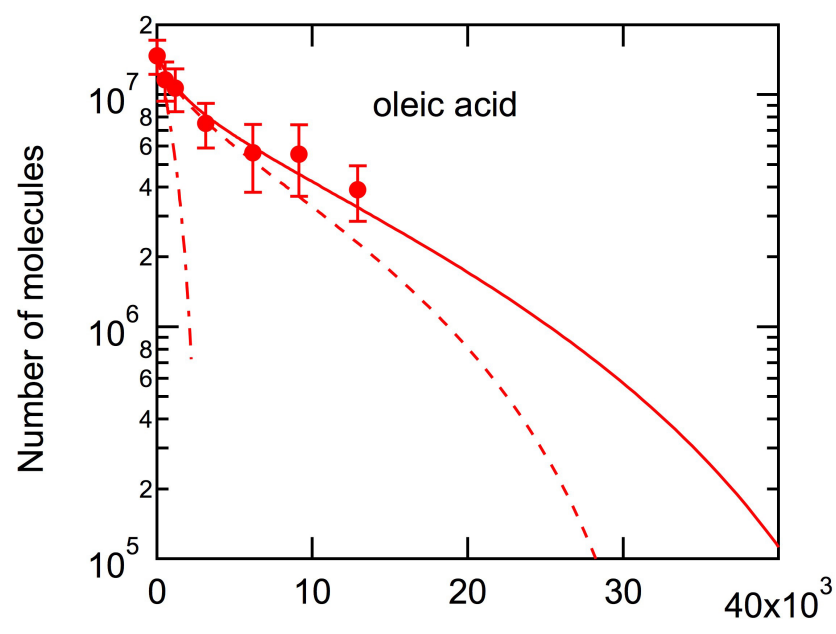

(a)
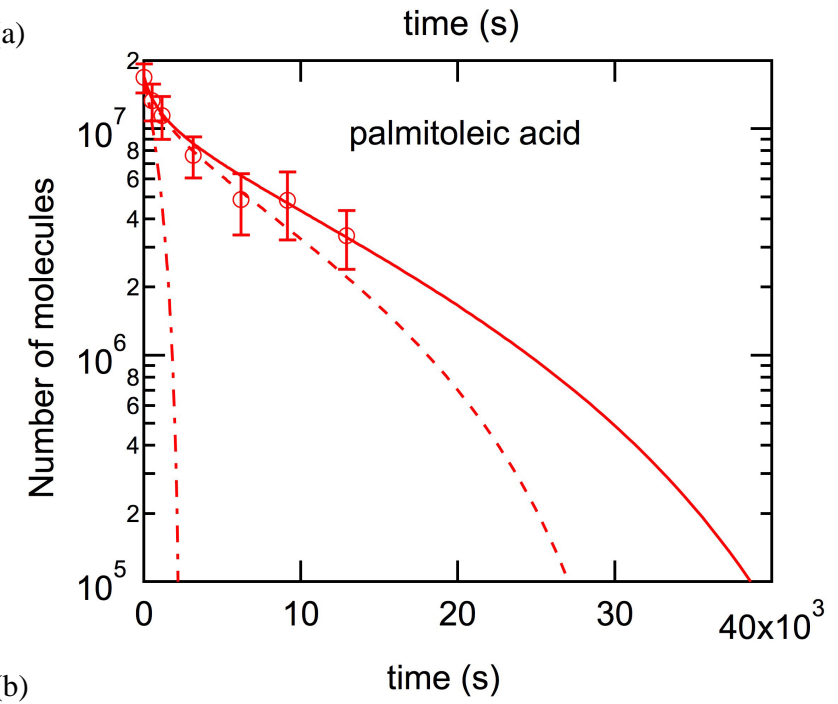

Fig. 1. Decays of numbers of molecules of (a) oleic and (b) palmitoleic acids in a 12-component aerosol matrix as a function of time. Symbols correspond to experimental data (Huff Hartz et al., 2007). The solid line is our best model fit with solidification (diffusivity-evolution model variant). The dashed line is a model fit of the semi-solid matrix assuming constant diffusivity (constantdiffusivity variant). The dot-dashed line ${ }^{1}$ represents a fit using a resistor-model formulation (K2-SUB).

are achieved when assuming successive solidification of the mixed particle (diffusivity-evolution model variant). At short reaction times, a fit that assumes a semi-solid matrix with constant diffusivity (dashed lines) matches the experimental data equally well. The constant-diffusivity fits lie outside the error limits of the experimental data for reaction times above ca. $10^{4} \mathrm{~s}$. The discrepancy between the two model variants is substantial for longer reaction times: complete consumption of the reactive acids (concentration $<1 \%$ of initial value) takes ca. $10^{4} \mathrm{~s}$ longer and the relative differences in concentrations increase progressively ( $>50 \%$ at $t: 2 \times 10^{4} \mathrm{~s}$ ) if the viscosity of the mixed aerosol increases during the ageing 
processes. The massive importance of the diffusivity of the particle matrix is illustrated in a comparison with the resistormodel formulation based K2-SUB model variant (Pfrang et al., 2010) where diffusion of the organic species in the bulk is not resolved (see dot-dashed lines in Fig. 1). This comparison illustrates that the assumption of homogeneous mixing and the application of the reacto-diffusive term of traditional resistor models are not appropriate for condensed phase reactants with low diffusivity in an amorphous semisolid multi-component aerosol matrix (confirming very recent findings by Shiraiwa et al., 2011b for protein ozonolysis). While there is clear experimental evidence for a retardation of the losses of oleic and palmitioleic acids (Huff Hartz et al., 2007), it should be noted that volatilization of reaction products - which is not considered in our approach - might affect the experimental data. The chemical composition of the particle will change during reaction and the extent of the deviation from initial particle composition will become increasingly significant for longer reaction timescales. Dominant initial products from the ozonolysis of oleic acid are known to be nonanal, which is likely to evaporate, as well as 9-oxononanoic, nonanoic, and azelaic acids in the liquid phase (e.g. Rudich et al., 2007; Vesna et al., 2009). We expect first-generation products of oleic acid ozonolysis other than nonanal to remain in the particle phase. No data is available on the product volatility or properties for the specific 12-component organic aerosol matrix simulated, so that the evaporation of products from particle to gas phase could not be considered in the current model. However, if crust formation is occurring the loss of volatiles would be restricted to the surface and near-surface bulk, i.e. the amount of volatile molecules relative to the total number of oleic and palmitoleic acid molecules in the particle would be small. The influence of the changing chemical composition of the particle surface on adsorbate-surface interactions i.e. on the surface accommodation coefficient can be taken into account by adjusting $\alpha_{\mathrm{s}, 0, \mathrm{O}_{3}}$ (see Pöschl et al., 2007, Pfrang et al., 2010 and Shiraiwa et al., 2010). For long reaction times, the increasing proportion of second- and third-generation products in the particle will also introduce additional uncertainties since branching ratios and molecular properties in such complex multi-component and multi-phase matrices are entirely unknown. Reliable predictions for such reaction systems require models able to resolve diffusivity of both gaseous and condensed phase reactants together with constraining experimental data.

Figure 2 compares surface and bulk accommodation with the uptake coefficient of ozone for constant-diffusivity (dashed lines) and diffusivity-evolution (solid lines) model variants. Surface accommodation, $\alpha_{\mathrm{s}, \mathrm{O}_{3}}$, remains at the initial surface accommodation value of unity throughout all model runs. Bulk accommodation, $\alpha_{\mathrm{b}, \mathrm{O}_{3}}$, is time independent as long as the diffusivity remains constant. At long reaction times, lower diffusion coefficients lead to a substantial reduction in bulk accommodation. This causes an earlier, but

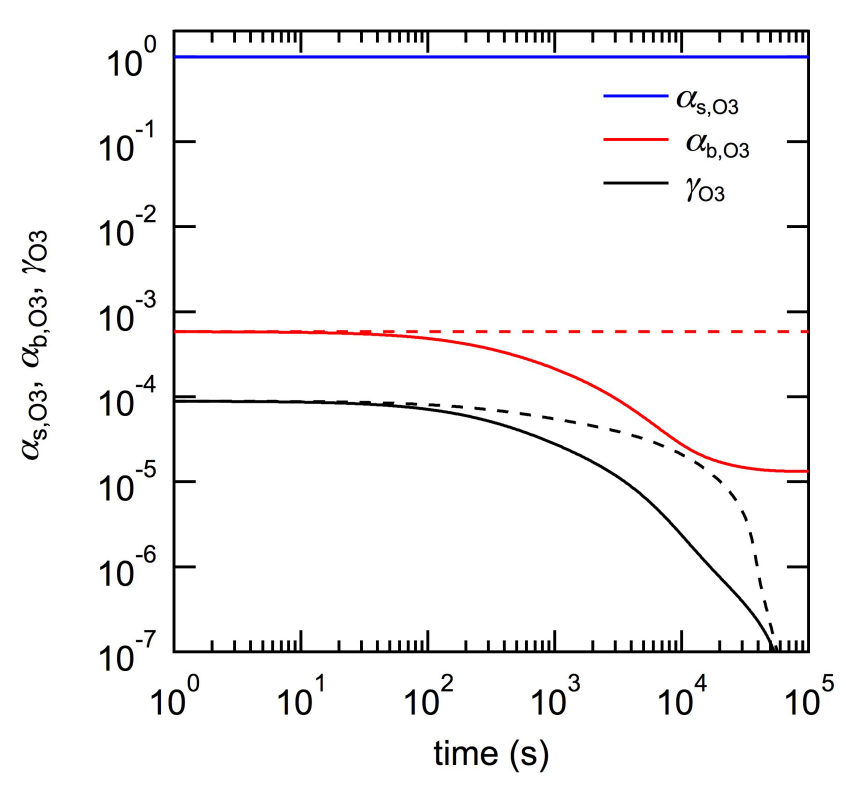

Fig. 2. Time evolution of surface and bulk accommodation as well as uptake coefficient for ozone for constant-diffusivity (dashed lines) and diffusivity-evolution (solid lines) model variants.

more gradual drop in $\gamma_{\mathrm{O}_{3}}$. Crust formation on the particle surface is illustrated by the plateau in $\alpha_{\mathrm{b}, \mathrm{O}_{3}}$ at long reaction times in the diffusivity-evolution model variant.

Figure 3 illustrates model surface parameters. Figure $3 \mathrm{a}$ shows the time evolution of surface concentrations of the reactants for both KM-SUB variants. While surface ozone is not affected by crust formation, the surface loss of the reactive organic species is significantly faster if the evolution of diffusivity is considered. In this case, transport between surface and bulk is slowed down due to the changes in diffusivity: transport is impeded 2-fold $\sim 500$ s oxidative ageing, 3-fold $\sim 1000$ s, 10 -fold $\sim 5000$ s and 20 -fold $\sim 10000$ s. The decay of reactive species on the particle surface is enhanced, because the surface cannot be renewed as bulk to surface transport of organics is inhibited by crust formation. Figure $3 b$ illustrates surface parameters for the diffusivityevolution model variant. The concentration fractions of products in the quasi-static surface layer $\left(f_{\mathrm{ss}}\right)$ and in the particle bulk $\left(f_{\mathrm{b}}\right)$ are illustrated in Figs. $3 \mathrm{~b}$ and 6 , respectively. Since the products are assumed to be (semi-)solid, we interpret these fractions as degrees of solidification with a value of unity corresponding to a complete conversion of reactants into products. $f_{\mathrm{ss}}$ approaching unity thus corresponds to the formation of a surface crust which would effectively shut down transport into the particle core due to the massively decreased diffusivity in the quasi-static surface layer. The degree of solidification $\left(f_{\mathrm{ss}}\right)$ is shown as blue line, while diffusivities at the surface for ozone and the organic species ( $\mathrm{Y}$; here oleic acid) are represented by black and red lines, respectively. One third of the surface solidifies already $\sim 500 \mathrm{~s}$ oxidative ageing; half of the surface $\sim 1000 \mathrm{~s}, 60 \% \sim 1800 \mathrm{~s}$, 


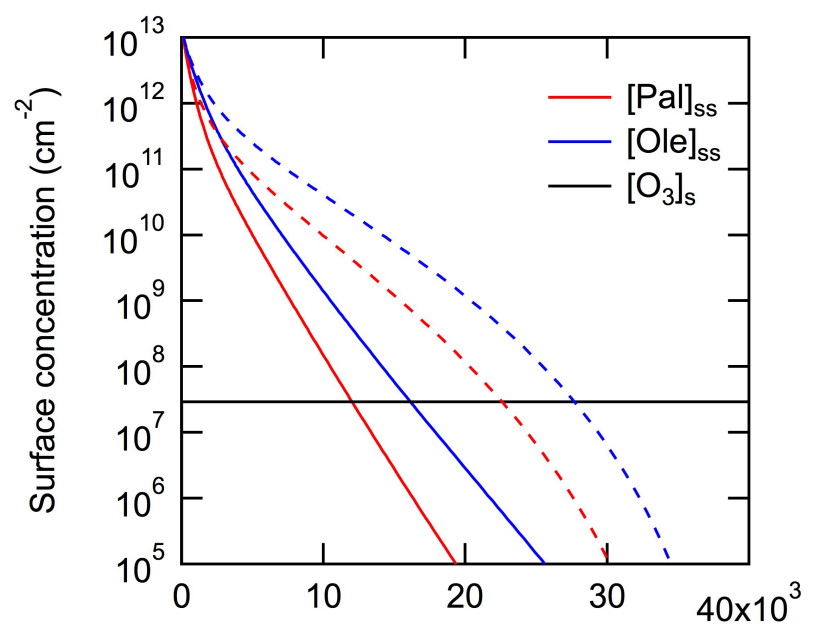

(a)

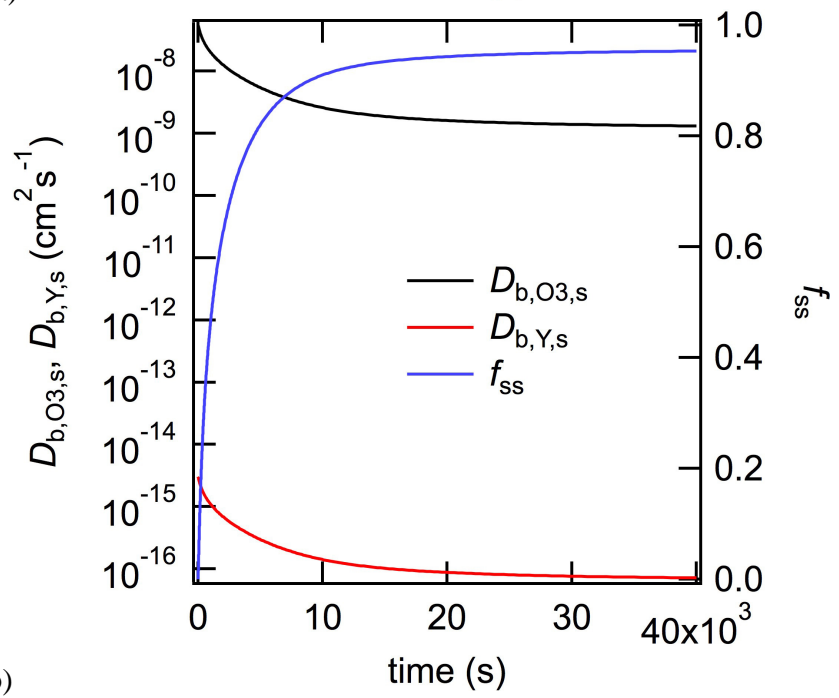

Fig. 3. (a) Time profiles of concentrations in the quasi-static surface layer of the reactive acids and ozone for constant-diffusivity (dashed lines) and diffusivity-evolution (solid lines) model variants. (b) Time evolution of diffusion coefficients for ozone and oleic acid as well as extent of solidification $\left(f_{\mathrm{ss}}\right)$ at the particle surface for the diffusivity-evolution model variant.

$80 \% \sim 4500$ s, $90 \% \sim 9100$ s, and: $95 \% \sim 30000$ s. Note that $30000 \mathrm{~s}$ correspond to about $8 \mathrm{~h}$, which is still much shorter than the typical atmospheric residence time of aerosol particles in the accumulation size range (several days). The solidification reduces the diffusivity of ozone and organic species at the particle surface by more than one order of magnitude.

Figure 4 shows the evolution of diffusivity in the bulk of the mixed particle for the best fit to the experimental data from Huff Hartz et al. (2007). The y-axis indicates the radial distance from the core of the aerosol particle $(r)$ normalized by the particle radius $\left(r_{\mathrm{p}}\right)$, ranging from the core $\left(r / r_{\mathrm{p}} \approx 0\right.$; not shown) to the particle surface $\left(r / r_{\mathrm{p}} \approx 1\right)$. The isolines in Fig. 4 illustrate the radial distribution and temporal evolution of the bulk diffusion coefficients of ozone (Fig. 4a) and the

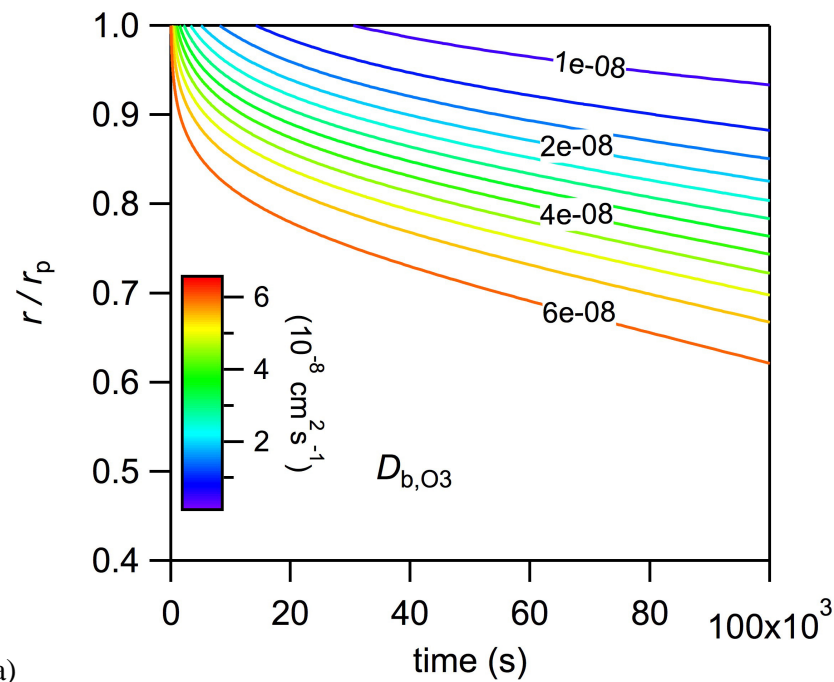

(a)

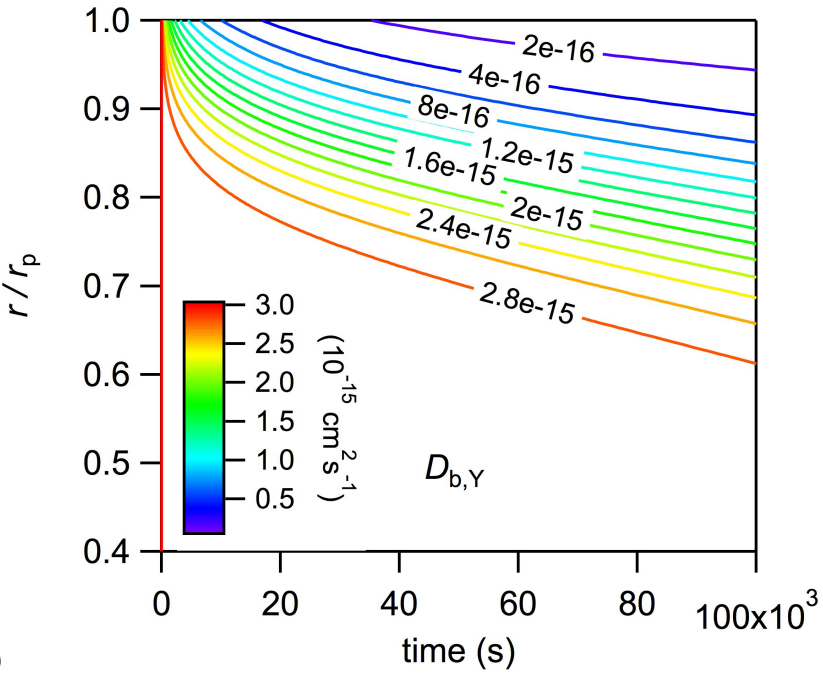

Fig. 4. Bulk diffusion coefficients of (a) ozone and (b) oleic acid as a function of time and depth in the $275 \mathrm{~nm}$-radius particle.

reactive organic species (here oleic acid; Fig. 4b) in the semisolid aerosol matrix. It is apparent that the diffusivities of both ozone and the organic species near the surface (up to: $120 \mathrm{~nm}$ into the particle) show considerable gradients while the diffusivities in the inner half of the particle remain largely unaffected by the oxidative ageing processes. Diffusion in the surface region is slowed down substantially: after 10 -h ageing we observe a 6-fold drop in the diffusion coefficient for ozone and a 10 -fold reduction for oleic acid comparing the top to a depth of $75 \mathrm{~nm}$ in the $275 \mathrm{~nm}$-radius particle. The crust formation clearly reduces the diffusivity. This effect becomes more pronounced at long reaction times.

Figure 5 displays the time evolution of the bulk concentrations of ozone and oleic acid. It is apparent that both ozone and organic species are not well-mixed and subject to considerable concentration gradients. The $\mathrm{O}_{3}$ gradient remains fairly large throughout the model run (ca. two orders 


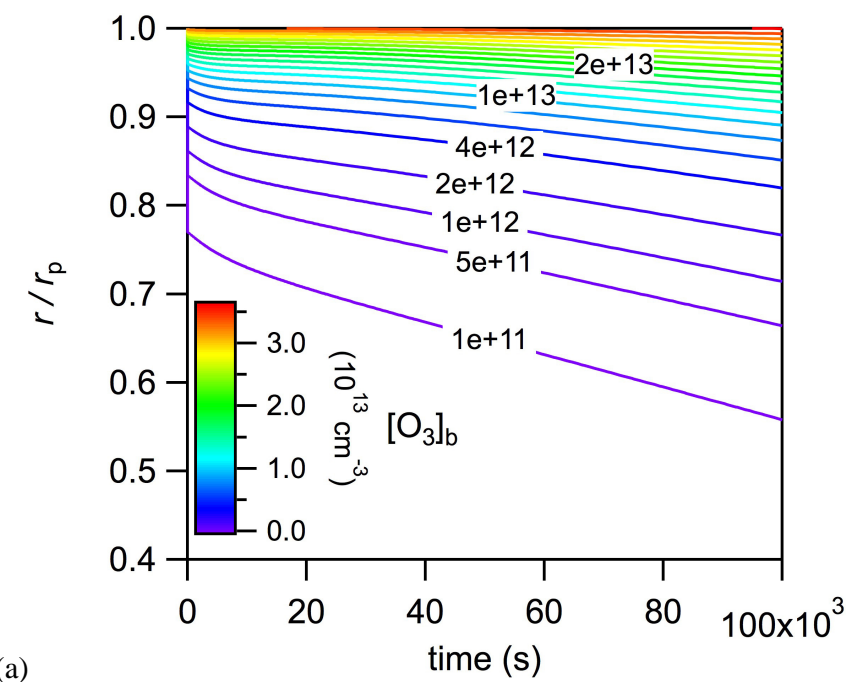

(a)

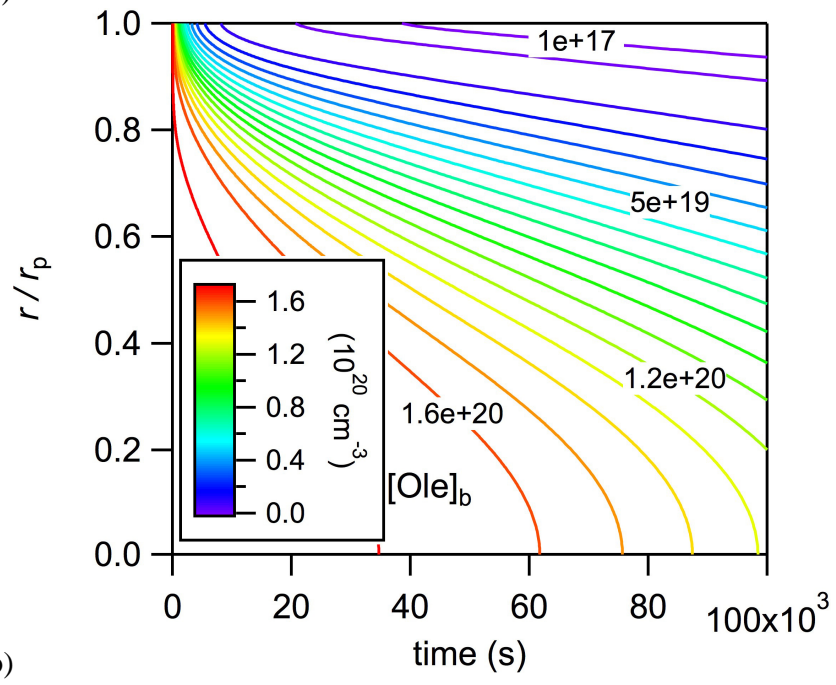

Fig. 5. Bulk concentration profiles of (a) ozone and (b) oleic acid for the diffusivity-evolution model. Equivalent plots for the constant-diffusivity model variant are presented in the Supplement in Fig. S1a and b.

of magnitude in the top $75 \mathrm{~nm}$ of the particle). Gradients in the organic compounds are generated very rapidly due to initially efficient loss at and near the particle surface. The oleic acid gradient in the top $75 \mathrm{~nm}$ reaches ca. three orders of magnitude and then decreases to ca. two orders of magnitude after one day of ageing. In particular the concentration gradient of the organic species leads to the breakdown of the resistor model treatment (see deviation of the dot-dashed lines in Fig. 1 from the experimental data) where organics are assumed to remain homogeneously mixed throughout the particle.

Figure 6 illustrates the extent of solidification in the particle bulk. Values close to unity illustrate the crust formation near the particle surface. $90 \%$ of the aerosol matrix becomes solid in the top $30 \mathrm{~nm}$ of the $275 \mathrm{~nm}$-radius particle already after 10 -h ageing. However, only $60 \%$ of the particle core

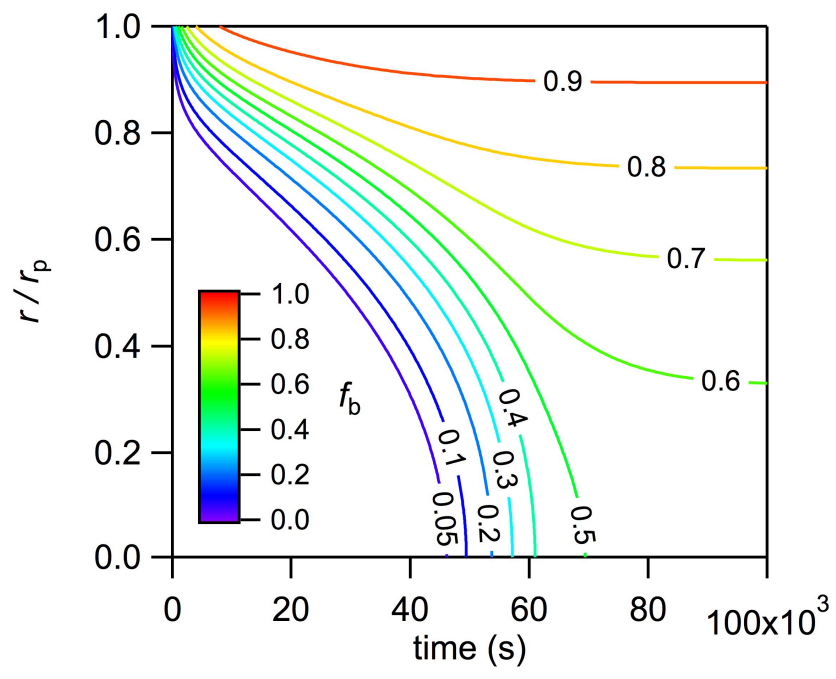

Fig. 6. Extent of solidification in the particle bulk, $f_{\mathrm{b}}$, as a function of time and depth in the $275 \mathrm{~nm}$-radius particle.

solidifies even after long-term atmospheric ageing ( $>1$ day) illustrating that the solid crust does not allow the reaction to continue efficiently inside the particle. This suggests that reactive species in the particle bulk are protected underneath a solid crust and may thus survive much longer in the atmosphere than anticipated based on chemical reactivity.

We demonstrate that our model allows flexible description of chemical and physical processes in multi-component aerosol matrices with evolving diffusivity. The best fit to experimental data is achieved for a solidifying aerosol forming a crust on the surface of the mixed particle. The impact of crust formation and diffusivity change on the reactive decay becomes larger with increasing reaction times. On typical atmospheric timescales crust formation would strongly affect the fate of reactive organic species with substantially extended lifetimes near the particle core. On the shorter timescales of experimental data (up to $10^{4} \mathrm{~s}$ ), a semi-solid matrix with constant diffusivity can also describe the observed reactive decays. Resistor model assumptions are inadequate even at short timescales, since limited diffusion of the organic species strongly affects particle ageing. These diffusivity effects cannot be described with traditional resistormodel formulations (compare Shiraiwa et al., 2011b). We demonstrate this directly by comparison of models with opposing assumptions for description of diffusivity. Chemical loss and physical retardation of composition changes in semisold aerosol matrices can be de-convoluted with our modelling approach. Solidification plays a substantial role at long reaction times highly relevant on atmospheric timescales. 


\section{Atmospheric implications}

In order to explore the effects of the diffusivity evolution on the chemical aging of semi-solid multi-component organic aerosols in the atmosphere, we have calculated the chemical half-life $\left(t_{1 / 2}\right)$ of the reactive fatty acids in the 12-component mixed particles exposed to atmospherically relevant gasphase ozone mixing ratios. $t_{1 / 2}$ is defined as the time after which the number of reactive fatty acid molecules in the particle has decreased to half of its initial value. The particle radius was set to $275 \mathrm{~nm}$, which corresponds to the size used in the simulated experiments (Huff Hartz et al., 2007) and is typical for the accumulation mode of atmospheric aerosols. $\left[\mathrm{O}_{3}\right]$ was varied in the range of 4 to $150 \mathrm{ppb}$, covering clean and polluted conditions in the lower atmosphere. The kinetic parameters were the same as in the model simulation of the experimental data (see Table 1).

For atmospheric interpretation of the results presented below, it should be noted that the model used in the present study has been optimized to simulate laboratory data for a 12-species organic aerosol matrix in dry conditions (Huff Hartz et al., 2007). While the 12 components have been chosen to mimic meat-cooking emission profiles containing the key unsaturated compounds commonly used as markers, in particular cholesterol as well as palmitoleic and oleic acids (Huff Hartz et al., 2007 and references therein), real meat cooking emissions are complex mixtures of hundreds of compounds and likely to interact with moisture present in the atmosphere. Particularly in highly humid conditions we would expect considerable deviations between our model results and the behaviour of cooking aerosol in the atmosphere, since hygroscopic growth can impact substantially on chemical ageing and atmospheric lifetimes of aerosols. Product volatilization in the complex 12-component aerosol mixture is also not considered here, mainly because of the lack of experimental data to constrain any modelling attempt. The evaporation and re-condensation of components and the resulting evolution of the chemical matrix may have considerable effects on chemical processes in these multi-species and multi-phase mixtures. While re-condensation is unlikely to be of importance in the experimental conditions where gaseous components originate from particles only, it may be important in complex atmospheric aerosol matrices.

Figure 7 shows the chemical half-life for oleic and palmitoleic acids contrasting diffusivity-evolution (solid lines) and constant-diffusivity (dashed lines) model variants. Model parameters are identical to those used in our best-fit scenario (see Table 1). As expected, $t_{1 / 2}$ decreases with increasing ozone gas phase concentration. Below $50 \mathrm{ppb}$, oleic and palmitoleic acids have half lives of several hours (up to $>0.5$ days at $4 \mathrm{ppb}$ ). At $150 \mathrm{ppb}$, half lives are below one hour. There are clear differences between the half lives obtained when assuming constant or evolving diffusivities. In clean and low-pollution environments, crust formation caused by diffusivity evolution of semi-solid aerosol matri-

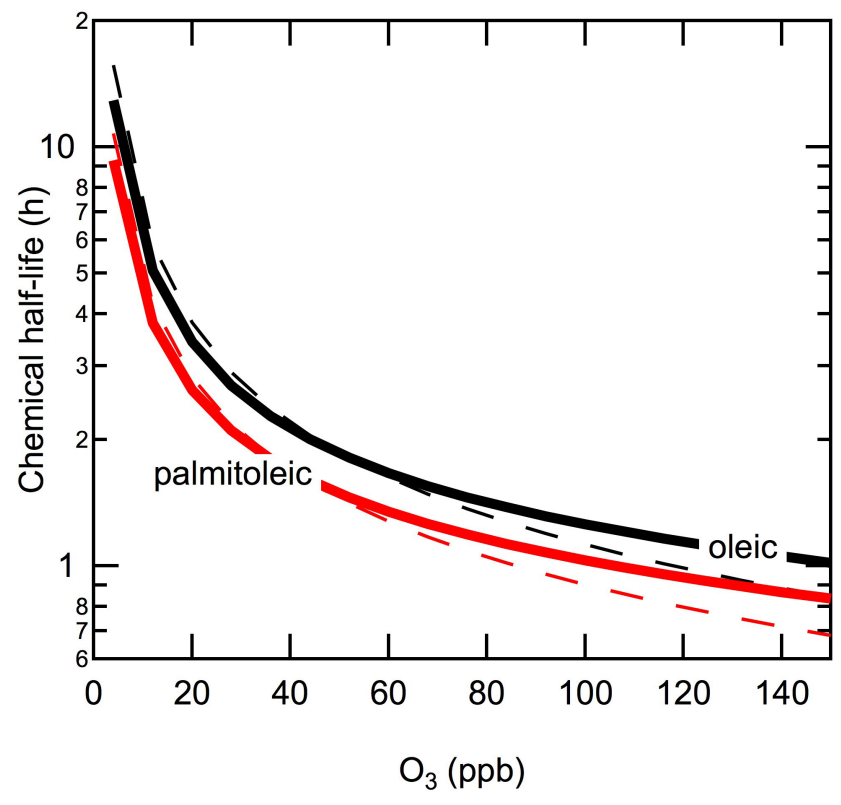

Fig. 7. Chemical half-life of oleic and palmitoleic acids, the most reactive components of the 12-component mixed aerosol matrix with a particle radius of $275 \mathrm{~nm}$ as a function of gas phase ozone mixing ratio. Bold solid lines represent results from the diffusivityevolution model variant and the dashed lines are obtained assuming constant diffusivity of the semi-solid aerosol matrix.

ces would lead to almost identical half lives of the reactive species while under polluted conditions $(>40 \mathrm{ppb}$ for palmitoleic acid and $>50 \mathrm{ppb}$ for oleic acid), lifetimes of reactive organics are increased significantly. The half-life increase becomes more pronounced at high $\left[\mathrm{O}_{3}\right]$. Overall, the half lives are increased when considering the crust formation which illustrates that reactive organic species can be protected underneath a surface crust in multi-component reactive aerosol matrices. This is consistent with atmospheric residence times of reactive species (in particular oleic acid) that are substantially longer than those obtained when considering chemical reactivity alone. The evolution of diffusivity in multi-component aerosol matrices clearly impacts on the fate of reactive components of organic aerosols.

The importance of diffusivity for the lifetime of the reactive species in multi-component aerosols is further illustrated in Fig. 8. Diffusion coefficients of water and photo-oxidants are typically $<10^{-10} \mathrm{~cm}^{2} \mathrm{~s}^{-1}$ in solid (Bird et al., 2007; Huthwelker et al., 2006), $10^{-10}-10^{-6} \mathrm{~cm}^{2} \mathrm{~s}^{-1}$ in semi-solid (Parker and Ring, 1995), and $10^{-6}-10^{-5} \mathrm{~cm}^{2} \mathrm{~s}^{-1}$ in liquid organic matrices (Bird et al., 2007; Johnson and Davis, 1996). We varied diffusivity of ozone between $10^{-5} \mathrm{~cm}^{2} \mathrm{~s}^{-1}$ (liquid matrix) to $10^{-10} \mathrm{~cm}^{2} \mathrm{~s}^{-1}$ in Fig. 8a. In Fig. $8 \mathrm{~b}$ we varied the initial diffusivity of the organic species in the range for semi-solids of $10^{-13}-10^{-20} \mathrm{~cm}^{2} \mathrm{~s}^{-1}$ (compare Shiraiwa et al., 2011b). 


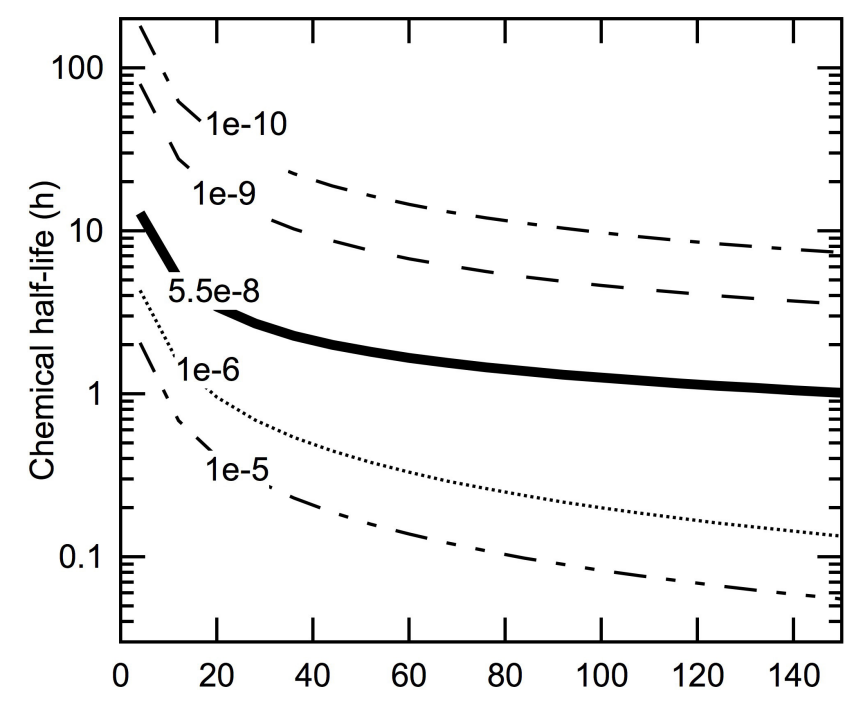

(a)

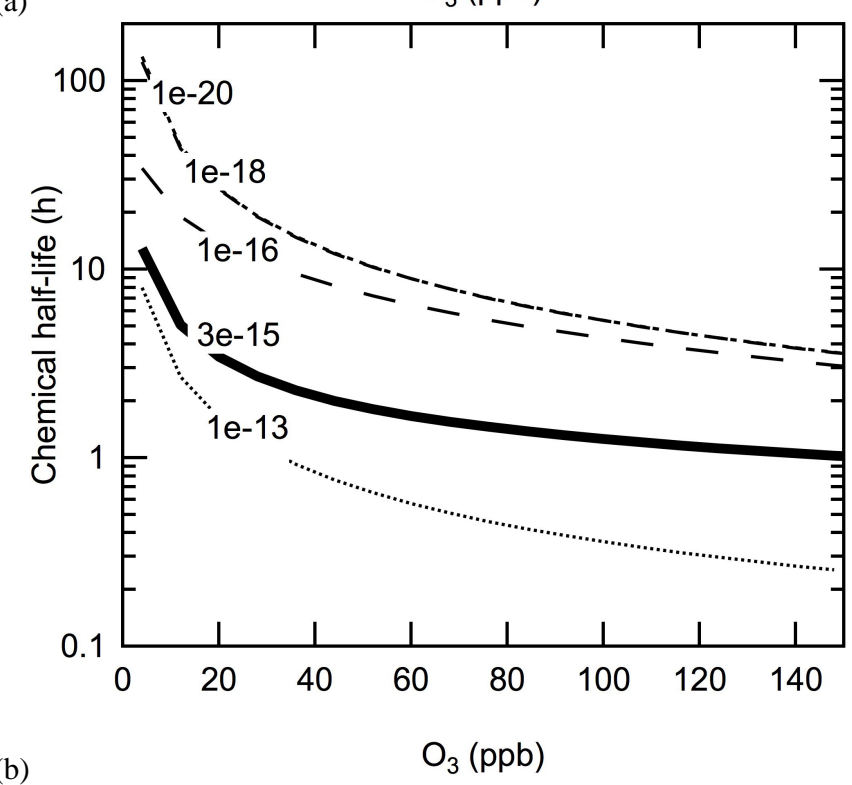

Fig. 8. Chemical half-life of oleic acid in the 12-component mixed aerosol matrix with a particle radius of $275 \mathrm{~nm}$ as a function of gas phase ozone mixing ratio. (a) With fixed $D_{\mathrm{b}, \mathrm{Y}, 0}$ $\left(3 \times 10^{-15} \mathrm{~cm}^{2} \mathrm{~s}^{-1}\right)$ and $D_{\mathrm{b}, \mathrm{O}_{3}, 0}$ are varied between $10^{-10_{-}}$ $10^{-5} \mathrm{~cm}^{2} \mathrm{~s}^{-1}$. (b) With fixed $D_{\mathrm{b}, \mathrm{O}_{3}, 0}\left(5.5 \times 10^{-8} \mathrm{~cm}^{2} \mathrm{~s}^{-1}\right)$ and $D_{\mathrm{b}, \mathrm{Y}, 0}$ are varied between $10^{-20}-10^{-13} \mathrm{~cm}^{2} \mathrm{~s}^{-1}$.

The chemical lifetimes converge for diffusivities of the organic species (see Fig. 8b) above $10^{-18} \mathrm{~cm}^{2} \mathrm{~s}^{-1}$ while they remain sensitive to the diffusivity of ozone (see Fig. 8a). The half lives span ca. three orders of magnitude for a given $\left[\mathrm{O}_{3}\right]$ depending on the diffusivity of the aerosol matrix. This underlines the importance of a detailed understanding of aerosol diffusivity to be able to establish lifetimes of reactive aerosol components in semi-solid matrices.
The importance of the phase state of aerosol particles (solid, semi-solid, or liquid) has been pointed out in previous studies (Knopf et al., 2005; Zahardis and Petrucci, 2007; Virtanen et al., 2010; Shiraiwa et al., 2011b). Recent kinetic model simulations showed that the atmospheric chemical lifetime of oleic acid in a liquid is only a few minutes, and it may increase to many hours if organic species are embedded in semi-solid aerosol matrices with low diffusivity (Shiraiwa et al., 2010). Our present study demonstrates that chemical reactions are hindered in amorphous semi-solid aerosol particles so that chemical half lives of many hours to a few days can be reached even for reactive unsaturated fatty acids in multi-component matrices (similar effects during protein ozonolysis have been described very recently by Shiraiwa et al., 2011b). The results of this study confirm that highly viscous semi-solid aerosol matrices with low diffusivity can effectively shield reactive organic compounds from degradation by atmospheric oxidants (Shiraiwa et al., 2010; George and Abbatt, 2010; Zobrist et al., 2011). Amorphous semi-solid or gel-like phases present in multi-component organic aerosol matrices thus require new formalisms for description of particle transformation.

\section{Conclusions}

Synthesising previous work in a detailed model analysis we demonstrate how variations in aerosol diffusivity can be described in multi-component semi-solid aerosol matrices. By extending the recently developed kinetic model (KM-SUB) for description of a 12-component mixture approximating atmospheric cooking aerosols we demonstrate how this model may be used to resolve flexibly surface and bulk processes in varying phases considering diffusivities altered by oligomerisation of reaction products.

We successfully resolve bulk diffusion and temporal change of diffusivity in a complex reactive multi-component aerosol matrix. We confirm that resistor-model formulations break down for the semi-solid aerosols and illustrate under which conditions changes in diffusivity play a key role for the fate of aged multi-component aerosol mixtures.

Atmospheric half lives for several components of a complex semi-solid aerosol matrix have been calculated for a wide range of $\left[\mathrm{O}_{3}\right]$ illustrating the impact of diffusivity and its evolution on the ageing of multi-component aerosols in atmospheric conditions. Impeded diffusivity in semi-solid matrices needs to be considered when estimating lifetimes for reactive species present in atmospheric aerosols.

Discrepancies between laboratory and field derived lifetimes of reactive aerosol components can be explained by trapping of the reactive species underneath a surface crust that limits diffusion into the aerosol core. We illustrate and quantify crust formation on the surface and in the nearsurface bulk as well as its impact on the reactive loss of components of the semi-solid aerosol matrix. Slow diffusion in a 
semi-solid aerosol matrix can explain the reduced bulk reactivity reported in Huff Hartz et al. (2007) without introducing an arbitrary change of chemical reaction rate coefficients.

While there is qualitative evidence for oligomer formation upon chemical ageing of atmospheric aerosols, further investigations are required to elucidate the importance of these processes both in the laboratory and in the atmosphere. Future studies should resolve the interactions and relative contributions of physical and chemical processes leading to changes in phase and diffusivity, i.e. the interplay of chemical reaction and transformation with changes in temperature and relative humidity.

\section{Appendix A}

\section{List of symbols}

\begin{tabular}{|c|c|c|}
\hline Symbol & Meaning & Unit \\
\hline$\alpha_{\mathrm{b}, \mathrm{O}_{3}}$ & Bulk accommodation coefficient of $\mathrm{O}_{3}$ & \\
\hline$\alpha_{\mathrm{s}, \mathrm{O}_{3}}$ & Surface accommodation coefficient of $\mathrm{O}_{3}$ & \\
\hline$\alpha_{\mathrm{s}, 0, \mathrm{O}_{3}}$ & $\begin{array}{l}\text { Surface accommodation coefficient of } \mathrm{O}_{3} \text { on an } \\
\text { adsorbate-free surface }\end{array}$ & \\
\hline$\alpha_{\mathrm{s}, 0, \mathrm{O}_{3}, \mathrm{Y}_{j}}$ & $\begin{array}{l}\text { Surface accommodation coefficient of } \mathrm{O}_{3} \text { on an } \\
\text { adsorbate-free surface composed of } \mathrm{Y}_{j}\end{array}$ & \\
\hline$\gamma_{\mathrm{O}_{3}}$ & $\begin{array}{l}\text { Uptake coefficient of } \mathrm{O}_{3} \text { (normalized by gas } \\
\text { kinetic flux of surface collisions) }\end{array}$ & \\
\hline$\tau_{\mathrm{d}, \mathrm{O}_{3}}$ & Desorption lifetime of $\mathrm{O}_{3}$ & $\mathrm{~s}$ \\
\hline$\tau_{\mathrm{d}, \mathrm{O}_{3}, \mathrm{Y} j}$ & Desorption lifetime of $\mathrm{O}_{3}$ on a surface composed of $\mathrm{Y}_{j}$ & s \\
\hline$\omega_{\mathrm{O}_{3}}$ & Mean thermal velocity of $\mathrm{O}_{3}$ in the gas phase & $\mathrm{cm} \mathrm{s}^{-1}$ \\
\hline$D_{\mathrm{b}, \mathrm{O}_{3}, 0}, D_{\mathrm{b}, \mathrm{Y}, 0}$ & Initial bulk diffusion coefficient of $\mathrm{O}_{3}$ and $\mathrm{Y}$ & $\mathrm{cm}^{2} \mathrm{~s}^{-1}$ \\
\hline $\begin{array}{l}D_{\mathrm{b}, \mathrm{O}_{3}, 0}(t) \\
D_{\mathrm{b}, \mathrm{Y}, 0}(t)\end{array}$ & $\begin{array}{l}\text { Time-dependent bulk diffusion coefficient } \\
\text { of } \mathrm{O}_{3} \text { and } \mathrm{Y}\end{array}$ & $\mathrm{cm}^{2} \mathrm{~s}^{-1}$ \\
\hline $\begin{array}{l}D_{\mathrm{s}, \mathrm{O}_{3}, 0}(t) \\
D_{\mathrm{S}, \mathrm{Y}, 0}(t)\end{array}$ & $\begin{array}{l}\text { Time-dependent surface diffusion coefficient } \\
\text { of } \mathrm{O}_{3} \text { and } \mathrm{Y}\end{array}$ & $\mathrm{cm}^{2} \mathrm{~s}^{-1}$ \\
\hline$f_{\mathrm{b}, n}$ & Extent of solidification in bulk layer $n$ & \\
\hline$f_{\mathrm{ss}}$ & Extent of solidification in the surface layer & \\
\hline$J_{\mathrm{b}, \mathrm{rd}, \mathrm{O}_{3}}$ & Reacto-diffusive flux of $\mathrm{O}_{3}$ in the particle bulk & $\mathrm{cm}^{-2} \mathrm{~s}^{-1}$ \\
\hline$k_{\mathrm{BR}, \mathrm{O}_{3}, \mathrm{Y}_{j}}$ & $\begin{array}{l}\text { Second-order rate coefficients for bulk reactions of } \\
\mathrm{O}_{3} \text { with } \mathrm{Y}_{j}\end{array}$ & $\mathrm{~cm}^{3} \mathrm{~s}^{-1}$ \\
\hline$k_{\mathrm{SLR}, \mathrm{O}_{3}, \mathrm{Y}_{q}}$ & $\begin{array}{l}\text { Second-order rate coefficients for surface layer } \\
\text { reactions of } \mathrm{O}_{3} \text { with } \mathrm{Y}_{q}\end{array}$ & $\mathrm{~cm}^{2} \mathrm{~s}^{-1}$ \\
\hline$K_{\text {sol, }, \mathrm{cc}, \mathrm{O}_{3}}$ & Gas-particle partitioning coefficient of $\mathrm{O}_{3}$ & \\
\hline$n$ & Number of bulk layers & \\
\hline$N_{\mathrm{Y}}$ & Total number of Y molecules & \\
\hline$r_{\mathrm{p}}$ & Particle radius & $\mathrm{cm}$ \\
\hline$[\mathrm{Ole}]_{\mathrm{b}}$ & Bulk phase number concentration of oleic acid & $\mathrm{cm}^{-3}$ \\
\hline$[\mathrm{Ole}]_{\mathrm{ss}}$ & $\begin{array}{l}\text { Surface number concentration of oleic acid } \\
\text { (quasi-static surface layer) }\end{array}$ & $\mathrm{cm}^{-2}$ \\
\hline$\left[\mathrm{O}_{3}\right]_{\mathrm{b}}$ & Bulk phase number concentration of $\mathrm{O}_{3}$ & $\mathrm{~cm}^{-3}$ \\
\hline$\left[\mathrm{O}_{3}\right]_{\mathrm{g}}$ & Gas phase number concentration of $\mathrm{O}_{3}$ & $\mathrm{~cm}^{-3}$ \\
\hline$\left[\mathrm{O}_{3}\right]_{\mathrm{gs}}$ & Near-surface gas phase number concentration of $\mathrm{O}_{3}$ & $\mathrm{~cm}^{-3}$ \\
\hline$\left[\mathrm{O}_{3}\right]_{\mathrm{s}}$ & Surface number concentration of $\mathrm{O}_{3}$ (sorption layer) & $\mathrm{cm}^{-2}$ \\
\hline$[\mathrm{Pal}]_{\mathrm{ss}}$ & $\begin{array}{l}\text { Surface number concentration of palmitoleic acid } \\
\text { (quasi-static surface layer) }\end{array}$ & $\mathrm{cm}^{-2}$ \\
\hline
\end{tabular}

\section{Supplementary material related to this article is available online at: http://www.atmos-chem-phys.net/11/ 7343/2011/acp-11-7343-2011-supplement. Dateinamevonsupplement.}

Acknowledgements. This work was supported by the Royal Society, NERC (grant no. NE/G000883/1), the European Integrated Project on Aerosol, Cloud, Climate and Air Quality Interactions
(036833-2 EUCAARI), and the Pan-European Gas-AerosolsClimate Interaction Study (PEGASOS). MS is supported by the Max Planck Graduate Center - Johannes Gutenberg University Mainz and the Ministry of Education, Culture, Sports, Science and Technology, Japan.

The service charges for this open access publication have been covered by the Max Planck Society.

Edited by: V.-M. Kerminen

\section{References}

Allan, J. D., Williams, P. I., Morgan, W. T., Martin, C. L., Flynn, M. J., Lee, J., Nemitz, E., Phillips, G. J., Gallagher, M. W., and Coe, H.: Contributions from transport, solid fuel burning and cooking to primary organic aerosols in two UK cities, Atmos. Chem. Phys., 10, 647-668, doi:10.5194/acp-10-647-2010, 2010.

Ammann, M. and Pöschl, U.: Kinetic model framework for aerosol and cloud surface chemistry and gas-particle interactions - Part 2: Exemplary practical applications and numerical simulations, Atmos. Chem. Phys., 7, 6025-6045, doi:10.5194/acp-7-6025-2007, 2007.

Andreae, M. O. and Rosenfeld, D.: Aerosol-cloud-precipitation interactions. Part 1. The nature and sources of cloud-active aerosols, Earth-Sci. Rev., 89, 13-41, 2008.

Bird, R. B., Stewart, W. E., and Lightfoot, E. N.: Transport Phenomena (2nd Ed.) (John Wiley \& Sons, Inc., New York), 2007.

Enami, S., Hoffmann, M. R., and Colussi, A. J.: Acidity enhances the formation of a persistent ozonide at aqueous ascorbate/ozone gas interfaces, P. Natl. Acad. Sci. USA, 105, 7365-7369, 2008.

Fuzzi, S., Andreae, M. O., Huebert, B. J., Kulmala, M., Bond, T. C., Boy, M., Doherty, S. J., Guenther, A., Kanakidou, M., Kawamura, K., Kerminen, V.-M., Lohmann, U., Russell, L. M., and Pöschl, U.: Critical assessment of the current state of scientific knowledge, terminology, and research needs concerning the role of organic aerosols in the atmosphere, climate, and global change, Atmos. Chem. Phys., 6, 2017-2038, doi:10.5194/acp-62017-2006, 2006.

George, I. J. and Abbatt, J. P. D.: Heterogeneous oxidation of atmospheric aerosol particles by gas-phase radicals, Nature Chem., 2, 713-722, 2010.

Gonzalez-Labrada, E., Schmidt, R., and DeWolf, C. E.: Kinetic analysis of the ozone processing of an unsaturated organic monolayer as a model of an aerosol surface, Phys. Chem. Chem. Phys., 9, 5814-5821, 2007.

Hallquist, M., Wenger, J. C., Baltensperger, U., Rudich, Y., Simpson, D., Claeys, M., Dommen, J., Donahue, N. M., George, C., Goldstein, A. H., Hamilton, J. F., Herrmann, H., Hoffmann, T., Iinuma, Y., Jang, M., Jenkin, M. E., Jimenez, J. L., Kiendler-Scharr, A., Maenhaut, W., McFiggans, G., Mentel, Th. F., Monod, A., Prévôt, A. S. H., Seinfeld, J. H., Surratt, J. D., Szmigielski, R., and Wildt, J.: The formation, properties and impact of secondary organic aerosol: current and emerging issues, Atmos. Chem. Phys., 9, 5155-5236, doi:10.5194/acp-95155-2009, 2009.

Huff Hartz, K. E. H., Weitkamp, E. A., Sage, A. M., Donahue, N. M., and Robinson, A. L.: Laboratory measurements of the oxidation kinetics of organic aerosol mixtures using a relative 
rate constants approach, J. Geophys. Res.-Atmos., 112, D04204, doi:10.1029/2006jd007526, 2007.

Huthwelker, T., Ammann, M., and Peter, T.: The uptake of acidic gases on ice, Chem. Rev., 106, 1375-1444, 2006.

Johnson, P. N. and Davis, R. A.: Diffusivity of Ozone in Water, J. Chem. Eng. Data, 41, 1485-1487, 1996.

Kalberer, M., Paulsen, D., Sax, M., Steinbacher, M., Dommen, J., Prévôt, A. S. H., Fisseha, R., Weingartner, E., Frankevich, V., Zenobi, R. and Baltensperger, U.: Identification of polymers as major components of atmospheric organic aerosols, Science, 303, 1659-1662, 2004.

King, M. D., Canosa-Mas, C. E., and Wayne, R. P.: Frontier molecular orbital correlations for predicting rate constants between alkenes and the tropospheric oxidants $\mathrm{NO}_{3}, \mathrm{OH}$ and $\mathrm{O}_{3}$, Phys. Chem. Chem. Phys., 1, 2231-2238, 1999.

King, M. D., Thompson, K. C., Ward, A. D., Pfrang, C., and Hughes, B. R.: Oxidation of biogenic and water-soluble compounds in aqueous and organic aerosol droplets by ozone: a kinetic and product analysis approach using laser Raman tweezers, Faraday Discuss., 137, 173-192, 2008.

King, M. D., Rennie, A. R., Thompson, K. C., Fisher, F. N., Dong, C. C., Thomas, R. K., Pfrang, C., and Hughes, A. V.: Oxidation of oleic acid at the air-water interface and its potential effects on cloud critical supersaturations, Phys. Chem. Chem. Phys., 11, 7699-7707, 2009.

King, M. D., Rennie, A. R., Pfrang, C., Hughes, A. V., Thomas, R. K., Dong, C. C., and Thompson, K. C.: Interaction of nitrogen oxide with a monolayer of oleic acid at the air-water interface: a simple proxy for atmospheric aerosol, Atmos. Environ., 44, 1822-1825, 2010.

Knopf, D. A., Anthony, L. M., and Bertram, A. K.: Reactive uptake of $\mathrm{O}_{3}$ by multicomponent and multiphase mixtures containing oleic acid, J. Phys. Chem. A, 109, 5579-5589, 2005.

Last, D. J., Nájera, J. J., Wamsley, R., Hilton, G., McGillen, M., Percival, C. J., and Horn, A. B.: Ozonolysis of organic compounds and mixtures in solution. Part I: Oleic, maleic, nonanoic and benzoic acids, Phys. Chem. Chem. Phys., 11, 1427-1440, 2009.

Lee, A. K. Y. and Chan, C. K.: Single particle Raman spectroscopy for investigating atmospheric heterogeneous reactions of organic aerosols, Atmos. Environ., 41, 4611-4621, 2007.

Marcolli, C., Luo, B. P., and Peter, T.: Mixing of the organic aerosol fractions: Liquids as the thermodynamically stable phases, J. Phys. Chem. A, 108, 2216-2224, 2004.

Martin, S. T.: Phase transitions of aqueous atmospheric particles, Chem. Rev., 100, 3403-3453, 2000.

McGillen, M. R., Archibald, A. T., Carey, T., Leather, K. E., Shallcross, D. E., Wenger, J. C., and Percival, C. J.: Structure-activity relationship (SAR) for the prediction of gas-phase ozonolysis rate coefficients: an extension towards heteroatomic unsaturated species, Phys. Chem. Chem. Phys., 13, 2842-2849, 2011.

Mikhailov, E., Vlasenko, S., Martin, S. T., Koop, T., and Pöschl, U.: Amorphous and crystalline aerosol particles interacting with water vapor: conceptual framework and experimental evidence for restructuring, phase transitions and kinetic limitations, Atmos. Chem. Phys., 9, 9491-9522, doi:10.5194/acp-9-9491-2009, 2009.

Moise, T. and Rudich, Y.: Reactive uptake of ozone by aerosolassociated unsaturated fatty acids: Kinetics, mechanism, and products, J. Phys. Chem. A, 106, 6469-6476, 2002.

Murray, B. J.: Inhibition of ice crystallisation in highly viscous aqueous organic acid droplets, Atmos. Chem. Phys., 8, 54235433, doi:10.5194/acp-8-5423-2008, 2008.

Nash, D. G., Tolocka, M. P., and Baer, T.: The uptake of $\mathrm{O}_{3}$ by myristic acid - oleic acid mixed particles: Evidence for solid surface layers, Phys. Chem. Chem. Phys., 8, 4468-4475, 2006.

Parker, R. and Ring, S. G.: Diffusion in maltose-water mixtures at temperatures close to the glass-transition, Carbohyd. Res., 273, 147-155, 1995.

Pfrang, C., King, M. D., Canosa-Mas, C. E., and Wayne, R. P.: Correlations for gas-phase reactions of $\mathrm{NO}_{3}, \mathrm{OH}$ and $\mathrm{O}_{3}$ with alkenes: an update, Atmos. Environ., 40, 1170-1179, 2006.

Pfrang, C., King, M. D., Canosa-Mas, C. E., Flugge, M., and Wayne, R. P.: Gas-phase rate coefficients for the reactions of $\mathrm{NO}_{3}, \mathrm{OH}$ and $\mathrm{O}_{3}$ with $\alpha, \beta$-unsaturated esters and ketones: structure-activity relations (SARs), Atmos. Environ., 41, 1792 1802, 2007.

Pfrang, C., King, M. D., Braeckevelt, M., Canosa-Mas, C. E., and Wayne, R. P., Gas-phase rate coefficients for reactions of $\mathrm{NO}_{3}$, $\mathrm{OH}, \mathrm{O}_{3}$ and $\mathrm{O}\left({ }^{3} \mathrm{P}\right)$ with unsaturated alcohols and ethers: Correlations and structure-activity relations (SARs), Atmos. Environ., 42, 3018-3034, 2008.

Pfrang, C., Shiraiwa, M., and Pöschl, U.: Coupling aerosol surface and bulk chemistry with a kinetic double layer model (K2-SUB): oxidation of oleic acid by ozone, Atmos. Chem. Phys., 10, 45374557, doi:10.5194/acp-10-4537-2010, 2010.

Pfrang, C. et al.: Kinetics and mechanism of the reaction of ozone with a monolayer of d-methyl oleate at the air-water interface studied by fast neutron reflectometry, in preparation, 2011.

Pöschl, U.: Atmospheric aerosols: Composition, transformation, climate and health effects, Angew. Chem. Int. Edit., 44, 75207540, 2005.

Pöschl, U., Rudich, Y., and Ammann, M.: Kinetic model framework for aerosol and cloud surface chemistry and gas-particle interactions Part 1: General equations, parameters, and terminology, Atmos. Chem. Phys., 7, 5989-6023, doi:10.5194/acp-75989-2007, 2007.

Rudich, Y.: Laboratory perspectives on the chemical transformations of organic matter in atmospheric particles, Chem. Rev., 103, 5097-5124, 2003.

Rudich, Y., Donahue, N. M., and Mentel, T. F.: Aging of organic aerosol: Bridging the gap between laboratory and field studies, Annu. Rev. Phys. Chem., 58, 321-352, 2007.

Seinfeld, J. H. and Pankow, J. F.: Organic atmospheric particulate material, Annu. Rev. Phys. Chem., 54, 121-140, 2003.

Shiraiwa, M., Garland, R. M., and Pöschl, U.: Kinetic double-layer model of aerosol surface chemistry and gas-particle interactions (K2-SURF): Degradation of polycyclic aromatic hydrocarbons exposed to $\mathrm{O}_{3}, \mathrm{NO}_{2}, \mathrm{H}_{2} \mathrm{O}, \mathrm{OH}$ and $\mathrm{NO}_{3}$, Atmos. Chem. Phys., 9, 9571-9586, doi:10.5194/acp-9-9571-2009, 2009.

Shiraiwa, M., Pfrang, C., and Pöschl, U.: Kinetic multi-layer model of aerosol surface and bulk chemistry (KM-SUB): the influence of interfacial transport and bulk diffusion on the oxidation of oleic acid by ozone, Atmos. Chem. Phys., 10, 3673-3691, doi:10.5194/acp-10-3673-2010, 2010.

Shiraiwa, M., Sosedova, Y., Rouviere, A., Yang, H., Zhang, Y., Abbatt, J. P. D., Ammann, M., and Pöschl, U.: Longlived reactive oxygen intermediates controlling the reaction 
of ozone with aerosol particles, Nature Chem., 3, 291-295, doi:10.1038/nchem.988, 2011a.

Shiraiwa, M., Ammann, M., Koop, T., and Pöschl, U.: Gas uptake and chemical aging of semi-solid organic aerosol particles, P. Natl. Acad. Sci. USA, 108(27), 11003-11008, 2011 b.

Stroeve, P.: On the Diffusion of Gases in Protein Solutions, Ind. Eng. Chem. Fund., 14, 140-141, 1975.

Thompson, K., Rennie, A., King, M., Hardman, S., Lucas, C., Pfrang, C., Hughes, B., and Hughes, A.: Reaction of a phospholipid monolayer with gas-phase ozone at the air-water interface: measurement of surface excess and surface pressure in real time, Langmuir, 26, 17295-17303, 2010.

Tong, H.-J., Reid, J. P., Bones, D. L., Luo, B. P., and Krieger, U. K.: Measurements of the timescales for the mass transfer of water in glassy aerosol at low relative humidity and ambient temperature, Atmos. Chem. Phys., 11, 4739-4754, doi:10.5194/acp-11-47392011, 2011.

Vaden, T. D., Imre, D., Beránek, J., Shrivastava, M., and Zelenyuk, A.: Evaporation kinetics and phase of laboratory and ambient secondary organic aerosol, P. Natl. Acad. Sci. USA, 108, 21902195, 2011.

Vesna, O., Sax, M., Kalberer, M., Gaschen, A., and Ammann, M.: Product study of oleic acid ozonolysis as function of humidity, Atmos. Environ., 43, 3662-3669, 2009.

Virtanen, A., Joutsensaari, J., Koop, T., Kannosto, J., Yli-Pirilä, P., Leskinen, J., Mäkelä, J. M., Holopainen, J. K., Pöschl, U., Kulmala, M., Worsnop, D. R., and Laaksonen, A.: An amorphous solid state of biogenic secondary organic aerosol particles, Nature, 467, 824-827, 2010.
Wayne, R. P.: Chemistry of Atmospheres, third ed., Oxford University Press, Oxford, 2000.

Xiao, S. and Bertram, A. K.: Reactive uptake kinetics of $\mathrm{NO}_{3}$ on multicomponent and multiphase organic mixtures containing unsaturated and saturated organics, Phys. Chem. Chem. Phys., 13, 6628-6636, doi:10.1039/c0cp02682d, 2011.

Zahardis, J. and Petrucci, G. A.: The oleic acid-ozone heterogeneous reaction system: products, kinetics, secondary chemistry, and atmospheric implications of a model system a review, Atmos. Chem. Phys., 7, 1237-1274, doi:10.5194/acp-7-1237-2007, 2007.

Zahardis, J., Geddes, S., and Petrucci, G. A.: The ozonolysis of primary aliphatic amines in fine particles, Atmos. Chem. Phys., 8, 1181-1194, doi:10.5194/acp-8-1181-2008, 2008.

Ziemann, P. J.: Aerosol products, mechanisms, and kinetics of heterogeneous reactions of ozone with oleic acid in pure and mixed particles, Faraday Discuss., 130, 469-490, 2005.

Zobrist, B., Marcolli, C., Pedernera, D. A., and Koop, T.: Do atmospheric aerosols form glasses?, Atmos. Chem. Phys., 8, 52215244, doi:10.5194/acp-8-5221-2008, 2008.

Zobrist, B., Soonsin, V., Luo, B. P., Krieger, U. K., Marcolli, C., Peter, T., and Koop, T.: Ultra-slow water diffusion in aqueous sucrose glasses, Phys. Chem. Chem. Phys., 13, 3514-3526, 2011. 